\title{
The Fabrication of Local Piezoelectric Sensors Using Hydraulic Pressing System Based on PLC
}

\author{
Levent Paralı ${ }^{1}$, İsrafil Şabikoğlu²* \\ ${ }^{1}$ Celal Bayar University, TMYO, Department of Electronic Automation, 0236313 55 02, levent.parali@cbu.edu.tr \\ ${ }^{2 *}$ Celal Bayar University, Facultu of Science and Art, 023620131 26, israfil.sabikoglu@cbu.edu.tr \\ *Corresponding Author
}

Received: 6 March 2017

Accepted: 19 June 2017

DOI: $10.18466 /$ cbayarfbe.339322

\begin{abstract}
In this study, the local PZT-PVDF composite sensors are produced. The PLC based hydraulic pressure system $(250 \mathrm{kgF})$ is as specially designed and fabricated to produce these sensors. The composite sensors are threated under pooling condition in silicon oil at 30 minutes, $120^{\circ} \mathrm{C}$. Frequency-voltage charactrestics of the piezoelectric sensor that integrated on vibration measurement system are defined, in addition $\mathrm{d}_{33}$ (piezoelectric coefficient), capacitance (C), and $\mathrm{Q}_{\mathrm{m}}$ (mechanical quality factor) values are determined. It is seen that, fabricated these sensors have 2.5 to $3.7 \mathrm{~V}_{\mathrm{pp}}$ (pick to pick) voltage at $10 \mathrm{~Hz}$ resonance frequency. $\mathrm{d}_{33}$ and $\mathrm{Q}_{\mathrm{m}}$ values of the mentioned sensors are characterized as 10.5-8.6 , 3.7-2.5, respectively. In lower frequency, these sensors which have maximum $3.7 \mathrm{~V}_{\mathrm{pp}}$ voltage may use as strain sensor, vibration sensor, atomic force microscope cantilever piezoelectric sensor, etc. For the first time, the local piezoelectric sensors are fabricated, and PLC based hydraulic pressure system is designed to produce them in Turkey.
\end{abstract}

Keywords: Fabrication, Hydraulic Pressure, PLC, Piezoelectric Sensor.

\section{Introduction}

Smart materials that has piezoelectric properties, find a diverse range of applications in the technology, industry and other research department [1, 2]. Lead zirconatetitanate (PZT) families are the most used in this area, because of they have high piezoelectric properties such as; piezoelectric coefficient $\mathrm{d}_{\mathrm{ij}}$, piezosensitivity $\mathrm{d}_{\mathrm{ij}} / \varepsilon \varepsilon_{0}$, Young modulus (Y), mechanical quality coefficient $\mathrm{Q}_{\mathrm{m}}$, electromechanical boundary coefficient $\mathrm{K}_{\mathrm{ij}}$ and small loss tangents etc. $[3,4]$.

There are many works about PZT and its applications, in addition, some scientist studied composite PZT material using Polyvinylidenefluoride (PVDF) polymer materials and investigated their electromechanical properties [5-10]. PZT and PVDF composite materials show different electromechanical feautres when it's evaluated together as compared to individual $[11,12]$.

Energy harvesting can be defined as converting ambient energies such as vibration, light, radio frequency energy, temperature etc. to available electric energy by using energy conversation materials like piezo based materials. The electric energy which is obtained from energy conversation materials are stroged on energy harvesting capasitors for power electric devices [13, 14].

Piezoelectric energy harvesting devices are captivating interest to decrease the power consumption and use of batteries which are consired cost, harmful to the environment, and limited life. Although a number of piezoelectric materials exist, the piezo based PZT and PVDF composites has become one of the most common materials for design of piezoelectric harvester devices. The combination of some excelent properties of the PZT and PVDF composites such as high flexibility, high toughness, high piezoelectric coefficient etc. make it a perfect choice for many applications including vibration sensor, dynamic strain gauges [15]. Current approaches on fabricating piezoelectric sensor are mainly based on a machining approach. The main steps of conventional fabricating system are based upon a hydraulic press. A hydraulic system can either be pumping controlled or valve controlled. Valve controlled systems use electro-hydraulic valves which are used to control the flow of fluid in the system [16-19].

In this study, firstly an industrial solution of the hydraulic pres control which has $250 \mathrm{kgF}$ is realized by using a programmable logic controllers (PLC), secondly, it is obtained local PZT-PVDF sensors via hydraulic pressure 
system by controlling with PLC. In addition, the piezoelectric properties of the sensors are determined.

\section{Material Method}

\subsection{Hydraulic Pressure System}

The hydraulic pressrue system covers some parts of industrial compenent such as; PLC (Programmeble logic controller) control unit included HMI (Human Machine Interface), electrical motor, proportional and directional valve, oil tank, pressure transducer (0-10 volt), pressure gauge etc, as shown in Figure 1.

PLC Control Unite of the hydraulic press is realized by using a programmable logic controller Simatic S7-1200, manufactured by Siemens. The controller program of S71200 and configuring of the HMI panel are built using SIMATIC STEP 7 Basic 10.5 software.

The hydraulic pressure system works with buton groups such as start, stop, emergency stop, and also it can be controlled as manually. The operator enters set up values of some parameter such as pressure, temperature, working time etc. by way of the HMI.

According to these parameter values, the system starts automatically working using by software commands into PLC. Placed powder mixtures (PZT + PVDF) into suitable a mold between upper and down jaws have been treated under working conditionals like pressure, temperature, working time. At the end of system's working time, the piezoelectric composite into mold is occurred as solid state. In the next process, lower and upper layers of obtained composite based piezoelectric sensors are attached the electrodes. Another process called poling is made by through High Voltage Amplifier (Gwinstek GPD-3303S Figure 2).

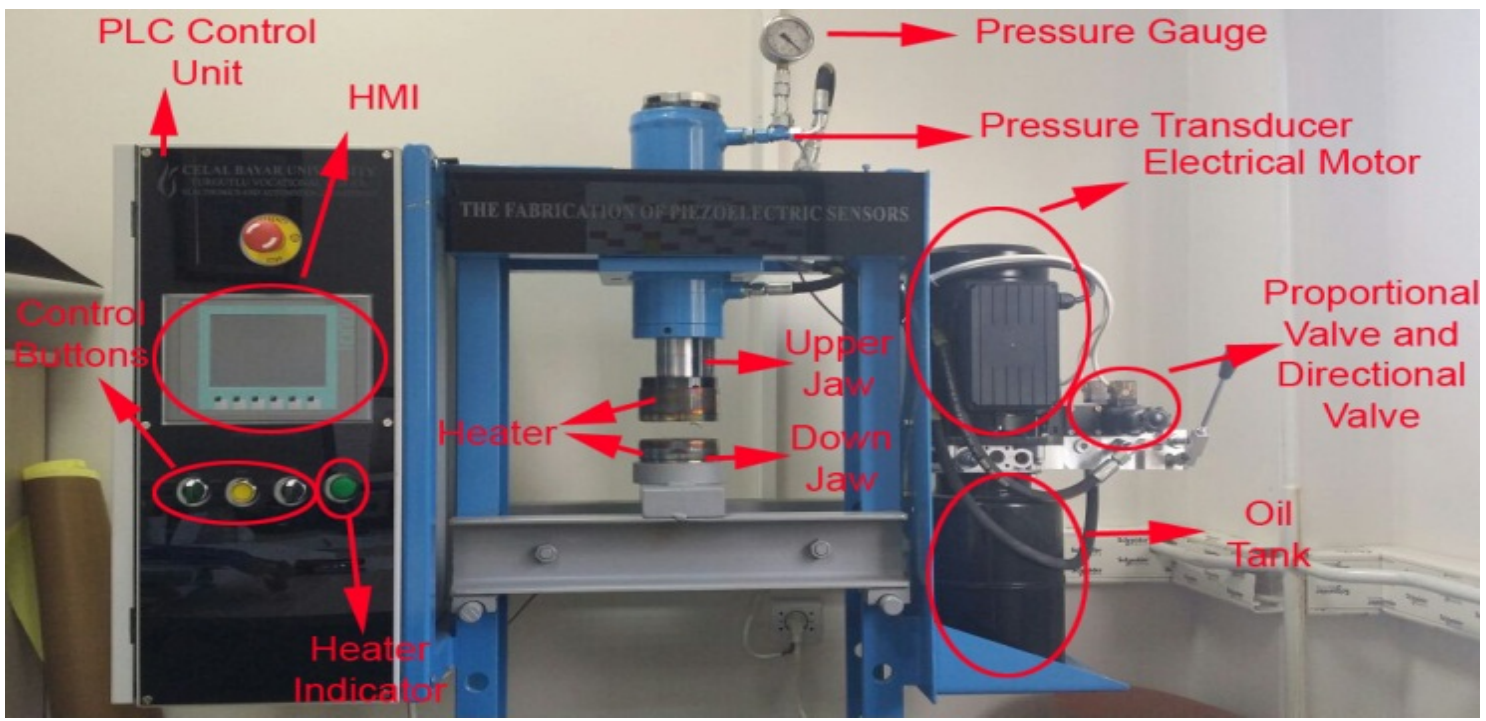

Figure 1. PLC based hydraulic pressure system.

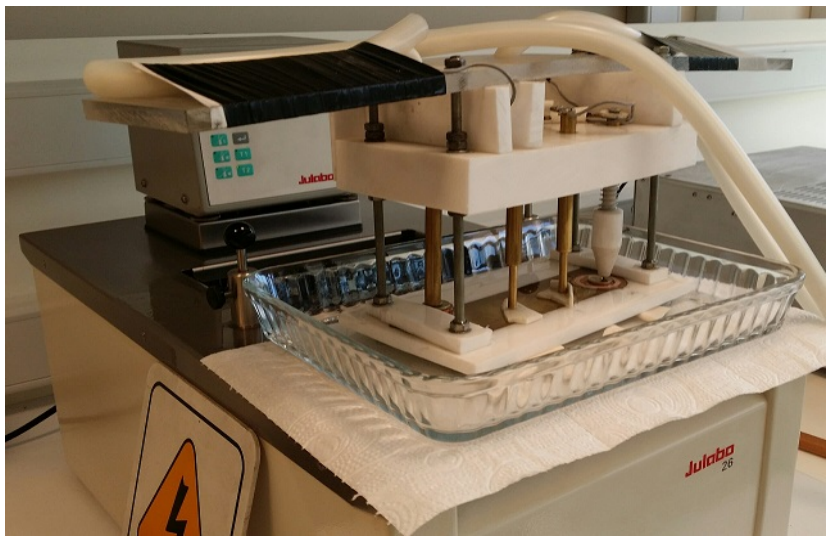

Figure 2. High voltage amplifier for poling process (Gwinstek GPD-3303S ).
The mentioned hydraulic system based on PLC actually has been realized in the Researcher and Development Laboratory at Electronics and Automation Department of Celal Bayar University, Turgutlu Vocational School. This system will be used for research purposes in the field of hydraulic systems control, as well as for training automation students.

\subsection{Preparing the Sensors}

The commercial PZT materials are used to obtain the composite sensors. Different type of PZT (PZT5A, PZT5H and PZT8 - APC Piezoelectric) 50\% weight and PVDF (Alfa Aesar) 50\% weight are used. PZT and PVDF materials are weighed in scales and then mixed in agate mortar carefully. Two kind of mold are made to preparing disc shape composite sensor. One of them is $32 \mathrm{~mm}$ and the 
other is $25 \mathrm{~mm}$ diameters. The mixed materials are placed into mold and then pressed with hydraulic pressure system in $160^{\circ} \mathrm{C}$ at 30 minutes. Six different PZT-PVDF composite materials are obtained as shown in Table 1 . The brass electrode is pasted on the surface of the sensor for pooling. The sensors are polarized at 1050 Volt electric field and $120^{\circ} \mathrm{C}$ in silicone oil. Fabricated sensors and their physical features are shown in Fig.3, Table 1, respectively.

Table 1. Physical features of PZT sensors.

\begin{tabular}{|c|c|c|c|c|c|c|}
\hline Name & PZT (50\%) & $\begin{array}{c}\text { Polymer } \\
(50 \%)\end{array}$ & $\begin{array}{c}\text { Diameter } \\
(\mathbf{m m})\end{array}$ & $\begin{array}{c}\text { Thickness }-\mathrm{d} \\
(\mu \mathrm{m})\end{array}$ & $\begin{array}{c}\text { Surface Area- } \\
\text { A }\left(\mathbf{m m}^{2}\right)\end{array}$ & $\mathrm{d} / \mathrm{A}\left(\mathbf{1 0}^{-4} \mathrm{~mm}^{-1}\right)$ \\
\hline PZT5A_1 & PZT 5A & PVDF & 32 & 321 & 803,84 & 3,99 \\
\hline PZT5A_2 & PZT 5A & PVDF & 25 & 402 & 490,63 & 8,19 \\
\hline PZT5H_1 & PZT 5H & PVDF & 32 & 318 & 803,84 & 3,95 \\
\hline PZT5H_2 & PZT 5H & PVDF & 25 & 399 & 490,63 & 8,13 \\
\hline PZT8_1 & PZT 8 & PVDF & 32 & 322 & 803,84 & 4,01 \\
\hline PZT8_2 & PZT 8 & PVDF & 25 & 402 & 490,63 & 8,19 \\
\hline
\end{tabular}

Table 2. Piezeoelectric properties of sensors.

\begin{tabular}{|c|c|c|c|c|c|}
\hline Name & $\mathbf{d}_{33}$ & $\begin{array}{c}\text { Capacitance- C } \\
\text { (pikoFarad) }\end{array}$ & $\mathbf{Q}_{\mathbf{m}}$ & $\mathbf{V}_{\mathbf{p p}}$ (Voltage) & Frequency (Hz) \\
\hline PZT5A_1 & 10.5 & 308 & 3.5 & 2.8 & 10 \\
\hline PZT5A_2 & 10.5 & 301 & 3.5 & 3.7 & 2.5 \\
\hline PZT5H_1 & 10 & 296 & 3.3 & 3.7 & 10 \\
\hline PZT5H_2 & 10 & 295 & 3.1 & 2.9 & 9.5 \\
\hline PZT8_1 & 8.6 & 288 & 3.1 & 3.4 & 9.5 \\
\hline PZT8_2 & 8.6 & 285 & & & \\
\hline
\end{tabular}
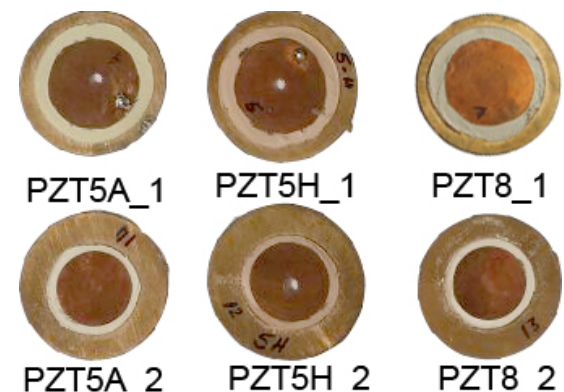

PZT5A 2

PZT.

Figure 3. Fabricated sensors.

\subsection{Vibration Measurement System}

The electrical performances of the piezoelectric sensors are analyzed by vibration measurement system (Fig.4). Voltages out put of the piezoelectric sensor are compared with each other according to vibration frequencies. LDS (Ling dynamic system) shaker is used to define vibration conditions. Vibration frequencies and amplitude are determined by WF1944 function signal generator, PA500L power amplifier is used to generate strong signal pro-

cessing. AC (Alternative Current) output voltages measurements both piezoelectric sensor and load cell during vibration are measured as no load with Agilent DSO-X 3014A digital stroge oscilloscope. Pre-stress value of the piezoelectric sensor is performed with Miniature DeltaTron TEDS Accelerometer Type 4508B load cell. In addition, the $\mathrm{d}_{33}$, capacitance, $\mathrm{Q}_{\mathrm{m}}$ values of the sensors are calculated using system.

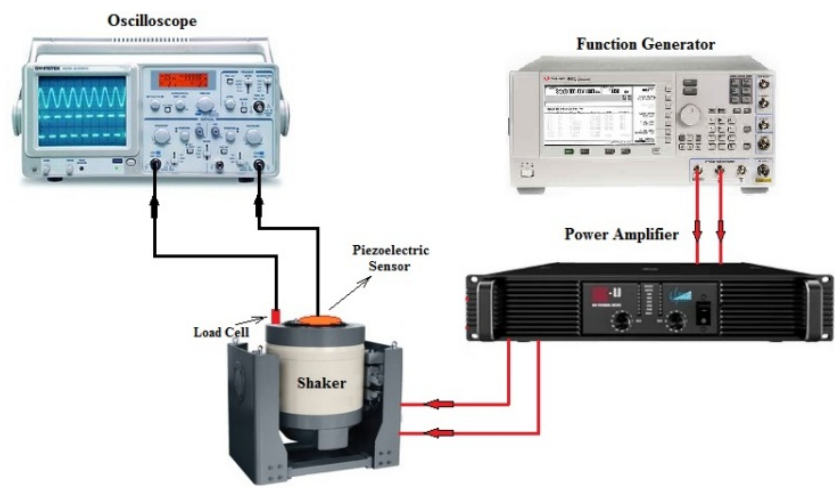

Figure 4. Vibration measurement system. 


\section{Results and Discussion}

The frequency vs voltage (pick to pick) behaviours of produced sensors are shown in Figure 5-9. It is seen that from Figure 5, 32mm diameters sensors have different voltage pick each other in $10 \mathrm{~Hz}$ frequency. PZT5H, PZT5A and PZT8 sensors indicate about 2.5, 2.8 and 2.9 $\mathrm{V}_{\mathrm{pp}}$ respectively. Different situation is occured for $25 \mathrm{~mm}$ diameters sensors in Fig.6. PZT5A and PZT5H sensors have almost same voltage (about $3.9 \mathrm{~V}_{\mathrm{pp}}$ ), and PZT8 sensor has $3.5 \mathrm{~V}_{\mathrm{pp}}$ in Fig.6. Therefore, the voltage pick values of $25 \mathrm{~mm}$ diameters sensors bigger than ones of the $32 \mathrm{~mm}$ diameters sensors.

The $\mathrm{d} / \mathrm{A}$ rate of the sensors are different for $32 \mathrm{~mm}$ and $25 \mathrm{~mm}$ diameters sensors. It can be come from different quality factor of the sensors. The $\mathrm{Q}_{\mathrm{m}}$ factors are calculated using FWHM of frequency-voltage graph of the sensors, and $\mathrm{d} / \mathrm{A}$ rates. In addition, the sensors have different thickness and surface areas (in Table 1) as well as sensors have different piezoelectric properties (Table 2).

When it is considering the PZT5As, PZT5Hs and PZT8s which have different diameters between each other in Figure 7, Figure 8, and Figure 9, it seems that the PZT+PVDF composites with $25 \mathrm{~mm}$ diameter have higher voltage values than that anothers for all PZT various. It can be concluded that the differences are come from surface area and the thickness of the sensors. In addition, piezoelectric coefficient $\left(\mathrm{d}_{33}\right)$ values of the sensors are very close to each other as well as mechanicality quality factors. It is seen that these sensors have similar piezoelectric properties, and this may be the 50\% PVDF used in composite. It is planned that the piezoelectric sensors will be produced by increasing rate of PZT in subsequent studies, and the energy capability of these sensors will be realized on energy harvesting system.

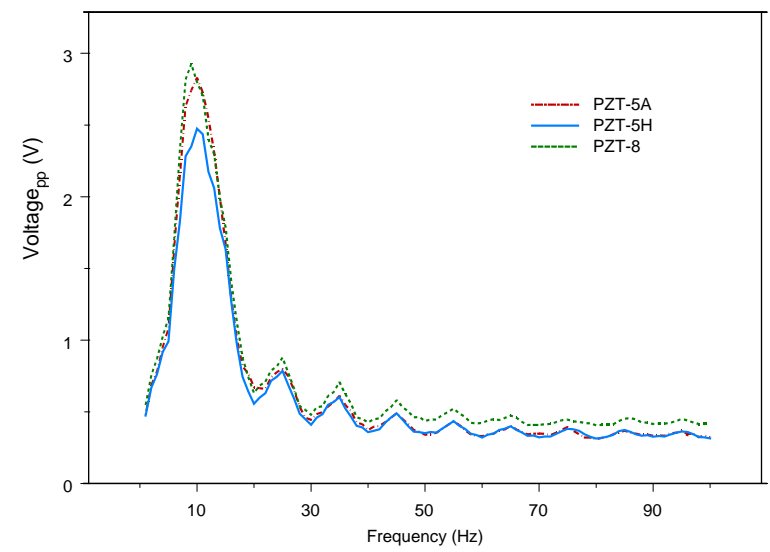

Figure 5. Frequency - Voltage graph of PZT sensors with 32mm diameter.

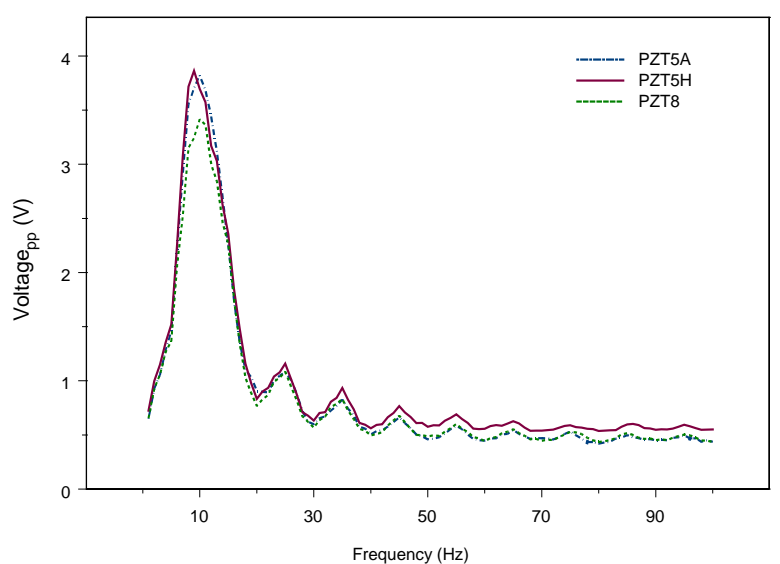

Figure 6. Frequency - Voltage graph of PZT sensors with $25 \mathrm{~mm}$ diameter.

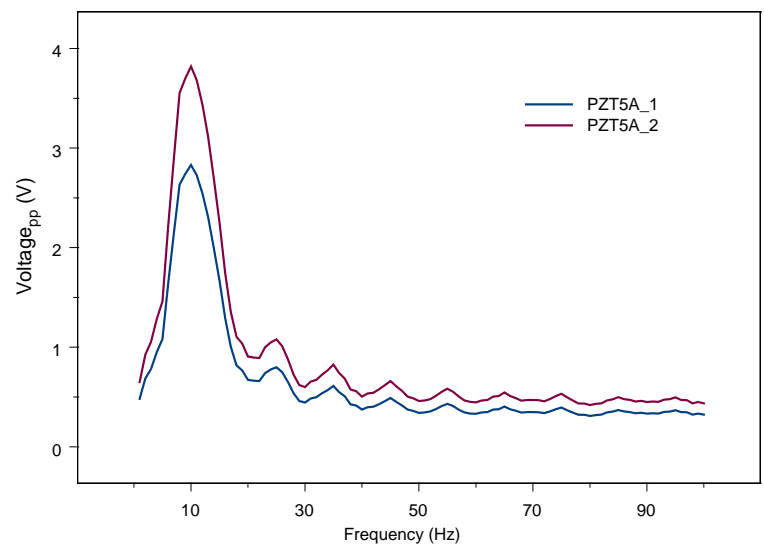

Figure 7. Frequency - Voltage graph of 32mm (PZT5A_1) and 25mm (PZT5A_2) diameters PZT sensors.

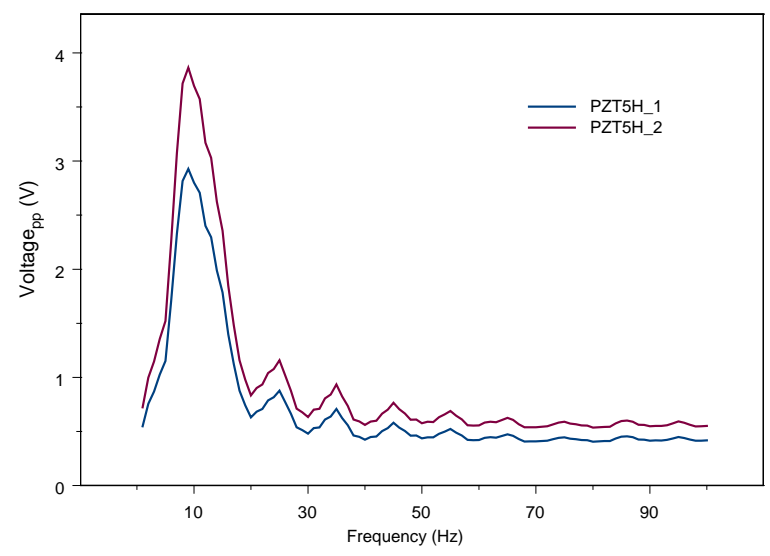

Figure 8. Frequency - Voltage graph of 32mm (PZT5H_1) and 25mm (PZT5H_2) diameters PZT sensors. 
sites, Nanomaterials and Nanotechnology, 2016; 620.

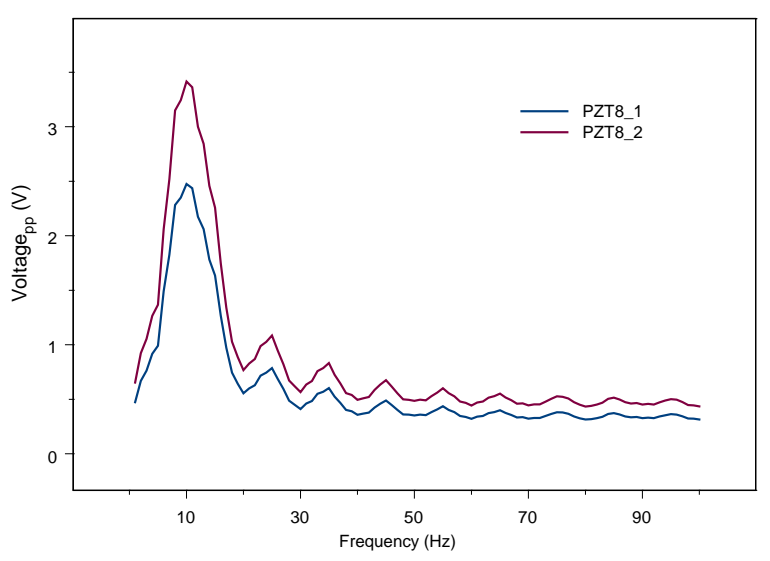

Figure 9. Frequency - Voltage graph of 32mm (PZT8_1) and 25mm (PZT8_2) diameters PZT sensors.

\section{Conclusion}

In this study, the local PZT composite sensors are produced by PLC controlled hydraulic pressure system, and unique pressure system is designed. It can produce sensors of various diamension using by pressure system, in addition, by making transformations in the pressure system, the series of production can be performed.

\section{Acknowledgements}

This work was supported by the Scientific ResearchCouncil of Celal Bayar University (Project No. 2015-016).

\section{References}

1. Zak, A.K., Gan, W.C., AbdMajid, W.H., Darroudi, M., Velayutham, T.S.; Experimental and theoretical dielectric studies of PVDF/PZT nanocomposite thin films, Ceramics International, 2011; 37(5) 16531660.

2. Jain, A., Prashanth, K.J., Sharma, A.K.R., ArpitJain, P.N.; Dielectric and Piezoelectric Properties of PVDF/PZT Composites: A Review. Polymer Engineering and Science, 2015; 55(7) 1-28.

3. Chu, S.Y., Chen, T.Y., Tsai, I.T., Water, W.; Doping effects of Nb additives on the piezoelectric and dielectric properties of PZT ceramics and its application on SAW device, Sensors and Actuators A, 2004; 113 198-203.

4. Bagirov, M.A., Nuraliev, N.A. Nuraliev and Kurbanov, M.A.; Soviet Physics-Technical Physics, 1972; 17 495-498.

5. Yun, J.S., Park, C.K., Jeong, Y.H., et al. The Fabrication and Characterization of Piezoelectric PZT/PVDF Electrospun Nanofiber Compo-
6. Huang, H.H., Chen, K.S., Design, analysis, and experimental studies of a novel PVDF-based piezoelectric energy harvester with beating mechanisms, Sensors and Actuators A-Physical, 2016; 238 317-328.

7. Gaur, A.M., Rana, D.S., Dispersion relations for $\mathrm{SH}$ waves propagation in a porous piezoelectric (PZT-PVDF) composite structure, Acta Mechanica, 2015; 22612 4017-4029.

8. Jain, A., Prashanth, K.J., Sharma, A.K., et al. Dielectric and piezoelectric properties of PVDF/PZT composites: A review, Polymer Engineering and Science, 2015; 557 1589-1616.

9. Tiwari, V., Srivastava, G., Structural, dielectric and piezoelectric properties of 0-3 PZT/PVDF composites, Ceramics International, 2015; 416 8008-8013.

10. Jaitanong, N., Yimnirun, R., Zeng, H.R., et al. Piezoelectric properties of cement based/PVDF/PZT composites, Materials Letters, 2014; 130 146-149.

11. Li, R., Zhang, L., Shi, Z., Pei, J., Effects of Coupling Agents on the Structure and Electrical Properties of PZT-Poly (VinylideneFluoride) Composites, Applied Sciences-Basel, 2016; 610282.

12. Tiwari, V., Srivastava, G., Enhanced dielectric and piezoelectric properties of 0-3 PZT/PVDF composites, Journal of Polymer Research, 2016; 23338.

13. Sodano, H.A., Inman, D.J., Park, G., A review of power harvesting from vibration using piezoelectric materials. Shock and Vibration Diggest, 2004; 36 197-205.

14. Bowen, C.R., Kim, H.A., Weaver, P.M., Dunn, S., Piezoelectric and ferroelectric materials and structures for energy harvesting applications. Energy and Environmental Science, 2014; 7 25-44.

15. Gad-el-Hak, M., MEMS: Design and Fabrication, CRC Press Inc., London, UK, 2005.

16. Walters, R.B., Hydraulic and electric-hydraulic control systems, Springer, 2000.

17. De Volder, M., Ceyssens, F., Reynaerts, D., and Puers, R., Design and characterisation of a hydraulic micro actuator fabricated by lithography, in Micro Electro Mechanical Systems, 2009. MEMS 2009. IEEE 22nd International Conference on, 2009; 451-454.

18. Adenuga, O.T., and Mpofu, K., Control system for electrohydraulic synchronization on RBPT, 47Th CIRP Conference on Manufacturing, 2014.

19. Chabok, H., Zhou, C., Chen, Y., Eskandarinazhad, A., Zhou, Q., and Shung, K., Ultrasound Transducer Array Fabrication Based on Additive Manufacturing of Piezocomposites, ASME/ISCIE International Symposium of Flexible Automation, 2012. 